\title{
Insulin-like growth factor-I signaling is modified during chondrocyte differentiation
}

\author{
Chanika Phornphutkul, Ke-Ying Wu, Xu Yang, Qian Chen and \\ Philip A Gruppuso
}

Departments of Pediatrics and Orthopedics, Rhode Island Hospital and Brown University, Providence, RI 02903, USA

(Requests for offprints should be addressed to C Phornphutkul, Division of Pediatric Endocrinology and Metabolism, Rhode Island Hospital, 593 Eddy Street, Providence, RI 02903, USA; Email: Chanika_Phornphutkul@brown.edu)

\begin{abstract}
Insulin-like growth factor-I (IGF-I) is a critical regulator of skeletal growth. While IGF-I has been shown to be a potent chondrocyte mitogen in vitro, its role in chondrocyte differentiation is less well characterized. We chose to study the action of IGF-I on an accepted model of chondrocyte differentiation, the ATDC5 cell line. Insulin concentrations sufficiently high to interact with the IGF-I receptor are routinely used to induce ATDC5 cells to differentiate. Therefore, we first examined the ability of IGF-I to promote chondrocyte differentiation at physiological concentrations. IGF-I could induce differentiation of these cells at concentrations below $10 \mathrm{nM}$. However, increasing IGF-I concentrations were less potent at inducing differentiation. We hypothesized that mitogenic effects of IGF-I might inhibit its differentiating effects. Indeed, the extracellular-signal-regulated kinase (ERK)-pathway inhibitor PD98059 inhibited ATDC5 cell DNA synthesis
\end{abstract}

while enhancing differentiation. This suggested that the ability of IGF-I to promote both proliferation and differentiation might require that its signaling be modulated through the differentiation process. We therefore compared IGF-I-mediated ERK activation in proliferating and hypertrophic chondrocytes. IGF-I potently induced ERK activation in proliferating cells, but minimal ERK response was seen in hypertrophic cells. In contrast, IGF-I-mediated Akt activation was unchanged by differentiation, indicating intact upstream IGF-I receptor signaling. Similar findings were observed in the RCJ3.1C $5 \cdot 18$ chondrogenic cell line and in primary chick chondrocytes. We conclude that IGF-I promotes both proliferation and differentiation of chondrocytes and that the differentiation effects of IGF-I may require uncoupling of signaling to the ERK pathway.

Journal of Endocrinology (2004) 183, 477-486

\section{Introduction}

Since the elucidation of the role of insulin-like growth factor-I (IGF-I) in the somatotropic actions of growth hormone $(\mathrm{GH})$, the role of this system in bone growth has been a subject of intense investigation (Lupu et al. 2001, van der Eerden et al. 2003). The classic somatomedin hypothesis proposed that pituitary-derived $\mathrm{GH}$ functions in an endocrine manner to stimulate the production of IGF-I, which then acts as a circulating hormone to stimulate growth at the growth plate (Daughaday \& Rotwein 1989). Subsequent studies led to a modification of the original hypothesis to include local production of IGF-I in response to GH. Thus, the somatomedin hypothesis was expanded to include autocrine/paracrine actions of IGF-I at the growth plate (Schlechter et al. 1986).

Several lines of evidence support a critical role for the GH/IGF system in skeletal growth. Genetically manipulated mice with GH deficiency exhibit postnatal growth failure (Lupu et al. 2001). IGF-I-null mice, which are born smaller than their wild-type littermates, show similar postnatal growth failure should they survive the newborn period (Liu et al. 1998). When IGF-I-null mice are treated with $\mathrm{GH}$, these animals fail to grow, thereby supporting the hypothesis that the effect of $\mathrm{GH}$ on postnatal skeletal growth is dependent on IGF-I (Liu et al. 1998). More recent studies on mice with inducible, liver-specific inactivation of the IGF-I gene (LI-IGF-I ${ }^{--}$) have shown that attenuated hepatic IGF-I production is compatible with normal postnatal growth, indicating the importance of autocrine/paracrine IGF-I production and action (Sjogren et al. 1999, Yakar et al. 1999).

GH receptor-null mice show severe postnatal growth retardation and extremely low circulating IGF-I levels. The growth plate in these animals narrows relative to wild-type animals starting at 2 weeks of age (Zhou et al. 1997). This is due to a reduction in the width of the so-called proliferative zone, the region of the growth plate in which chondrocytes are undergoing cell division. The hypertrophic zone, the portion of the growth plate in 
which chondrocytes increase in volume, is also reduced. When IGF-I is given to these animals, bone length increases and both the proliferative and hypertrophic zone widths are fully restored.

The models described above provide evidence that IGF-I may regulate both chondrocyte proliferation and hypertrophy. Studies on several chondrocyte cell lines have demonstrated that IGF-I is a potent mitogen for these cells (Ohlsson et al. 1994, Cancedda et al. 1995). However, few data are available indicating how IGF-I mitogenic effects are mediated and through what pathways potential IGF-I effects on chondrocyte proliferation and hypertrophy are transduced.

As noted above, the growth plate encompasses three defined zones in which proliferation, growth arrest and terminal differentiation occur. In the proliferative zone, the chondrocytes actively divide and give rise to columns of flattened cells secreting hyaline extracellular matrix rich in type II collagen. Differentiation occurs in the hypertrophic zone, which begins beyond a point at which the chondrocytes undergo growth arrest. This zone is marked by collagen type $\mathrm{X}$ expression. In addition, growth plate chondrocytes synthesize large amounts of chondroitin 4and 6-sulfate as well as keratan sulfate, all of which can be detected using Alcian Blue or toluidine staining (Chang et al. 1998).

Many hormones, growth factors and transcription factors have been shown to regulate chondrocyte differentiation (Kronenberg 2003). These include fibroblast growth factor, parathyroid hormone-related peptide, bone morphogenic protein, transforming growth factor- $\beta$ and the transcription factors SOX9 and Runx2. In the presence of a mutation in one of these transcription factors or in a receptor for one of the aforementioned growth factors, chondrodysplasia occurs. In contrast, the growth plate of animals in which the function of the GH/IGF system is altered appears histologically normal (Zhou et al. 1997). As a consequence, the biological importance of IGF-I on skeletal growth and differentiation may have been underestimated (Van Wyk \& Smith 1999).

Recent advances have been made in understanding mechanisms of IGF-I signal transduction (Benito et al. 1996, Werner \& Le Roith 2000). It is well established that IGF-I mitogenic effects are mediated, at least in part, by the members of the mitogen-activated protein kinase family, termed extracellular-signal-regulated kinase 1 and 2 (ERK1 and ERK2), as well as by the activation of phosphoinositide 3-kinase (PI 3-kinase) and Akt. The mechanisms by which IGF-I promotes the differentiation of various mesenchymal cell types, including adipocytes and cardiomyocytes (Boney et al. 1996, Milasincic et al. 1996, Boney et al. 1998), are also under investigation. All of these cell types have in common a requirement that cell-cycle arrest occur prior to progression to differentiation. The established role of IGF-I in bone growth taken together with findings in other mesenchymal cells led us to postulate that, in chondrocytes, IGF-I exerts dual functions as a mitogenic agent and a differentiation factor. We further postulated that IGF-I signaling would be modulated during chondrocyte development and that this modulation would prevent the mitogenic signals from interfering with the promotion of differentiation. For most of our studies, we utilized the ATDC5 cell line (Atsumi et al. 1990), a well-characterized chondrogenic cell line derived from a mouse teratocarcinoma. To assess the broader relevance of our findings, our observations were extended to a second chondrocyte cell line, RCJ3·1C5.18 cells, as well as primary chick chondrocytes.

\section{Materials and Methods}

\section{Materials}

Tissue-culture reagents, reverse transcriptase PCR reagents, Taq DNA polymerase and custom primers were obtained from Invitrogen (Carlsbad, CA, USA). X-Omat AR film and Enhanced Chemiluminescence Plus (ECL Plus) reagents were purchased from Amersham (Piscataway, NJ, USA). [ $\left.{ }^{3} \mathrm{H}\right]$ Thymidine was purchased from DuPont Company (Boston, MA, USA). Electrophoresis reagents and PVDF membrane were obtained from BioRad (Hercules, CA, USA). Anti-Akt and anti-phospho-Akt antibodies were purchased from Cell Signaling Technology (Beverly, MA, USA). AntiERK1/2 and anti-phospho-ERK1/2 were obtained from Upstate Biotechnology (Lake Placid, NY, USA). Human recombinant IGF-I and the IGF-I analog [ $\left.\mathrm{Arg}^{3}\right]$ IGF-I were obtained from GroPep (Adelaide, Australia). Purified porcine insulin was obtained from Elanco Products (Indianapolis, IN, USA). PD98059 was from Calbiochem (La Jolla, CA, USA). Holo-transferrin, dexamethasone, ascorbic acid, $\beta$-glycerophosphate and sodium selenite were purchased from Sigma (St Louis, MO, USA). TriReagent was obtained from Molecular Research Center (Cincinnati, OH, USA).

\section{Cell-culture conditions}

The ATDC5 cell line was obtained from the Riken Cell Bank (Tsukuba, Japan). Cells were grown in six-well plates and cultured in maintenance medium consisting of a 1:1 mixture of Dulbecco's modified Eagle's medium and Ham's F-12 medium containing 5\% fetal bovine serum, $10 \mu \mathrm{g} / \mathrm{ml}$ holo-transferrin, $3 \times 10^{-8} \mathrm{M}$ sodium selenite, $50 \mu \mathrm{g} / \mathrm{ml}$ penicillin, $100 \mu \mathrm{g} / \mathrm{ml}$ streptomycin and $0.25 \mu \mathrm{g} / \mathrm{ml}$ amphotericin $\mathrm{B}$ at $37^{\circ} \mathrm{C}$ in a humidified atmosphere of $5 \% \mathrm{CO}_{2}$ in air (Atsumi et al. 1990). To study proliferation, cells were plated at $6.4 \times 10^{3} \mathrm{cells} / \mathrm{cm}^{2}$ but studied at $70-80 \%$ confluence. To study hypertrophic cells, chondrogenesis was first induced by plating the cells at the same density and allowing them to proliferate until 
they reached confluence. This was accomplished using medium supplemented with either $10 \mu \mathrm{g} / \mathrm{ml}$ porcine insulin or various concentrations of IGF-I or $\left[\mathrm{Arg}^{3}\right]$ IGF-I. Media were replaced every other day. For all acute signaling studies, cells were placed in serum-free medium with $0 \cdot 1 \%$ BSA for $4 \mathrm{~h}$ prior to use.

RCJ3 1 C $5 \cdot 18$ cells, provided generously by Dr Jane E. Aubin (University of Toronto, Toronto, Ontario, Canada), were grown in $\alpha$-minimal essential medium supplemented with $15 \%$ heat-inactivated fetal bovine serum, $10^{-7} \mathrm{M}$ dexamethasone, $2 \mathrm{mM}$ sodium pyruvate, $50 \mu \mathrm{g} / \mathrm{ml}$ penicillin, $100 \mu \mathrm{g} / \mathrm{ml}$ streptomycin, and $0 \cdot 25 \mu \mathrm{g} / \mathrm{ml}$ amphotericin B. To study proliferation, cells were used at 70-80\% confluence. To induce chondrogenesis, fresh medium containing $50 \mu \mathrm{g} / \mathrm{ml}$ ascorbic acid and $10 \mu \mathrm{M}$ $\beta$-glycerophosphate was added after cells reached confluence. Media were replaced every other day and cells were harvested at 2 weeks (Grigoriadis et al. 1996).

Primary chick chondrocytes were isolated and cultured as described previously (Zhen et al. 2001). Chicken hypertrophic chondrocytes were obtained from the cephalic part of sternal cartilage from 17-day-old embryonic chicken. Proliferating chondrocytes were obtained from the caudal part of the cartilage. Cells were studied at $70-80 \%$ confluence and maintained in Ham's F-12 medium containing 10\% fetal bovine serum. For all acute signaling studies, cells were placed in serum-free medium with $0 \cdot 1 \%$ BSA for $4 \mathrm{~h}$ prior to their use.

\section{Histochemical quantitation of chondrocyte differentiation}

Accumulation of the mucopolysaccharides associated with chondrocyte differentiation was assessed by staining of cell monolayers with Alcian Blue (Atsumi et al. 1990). Cells were first rinsed with PBS three times, then fixed with $100 \%$ methanol for $10 \mathrm{~min}$ at $-20^{\circ} \mathrm{C}$. Staining was accomplished by applying a solution of $0 \cdot 1 \%$ Alcian Blue $8 \mathrm{GX}$ in $0.1 \mathrm{M} \mathrm{HCl}$ to the cells for $2 \mathrm{~h}$ at room temperature. To quantify the intensity of the staining, the stained culture plates were rinsed with PBS three times and each well extracted with $1 \mathrm{ml} 6 \mathrm{M}$ guanidine/ $\mathrm{HCl}$ overnight at room temperature. The optical density of extracted dye was measured at $650 \mathrm{~nm}$. Total cellular material was quantified in parallel by staining with Neutral Red, which is a weak base that is taken up by viable cells (Kull \& Cuatrecasas 1983). The detection of cellular Neutral Red content was measured as optical density at $550 \mathrm{~nm}$ of the same extracts used for Alcian Blue quantification. This method was used because it allowed us to combine analyses for an indicator of cell growth (proliferation and/or hypertrophy) with quantification of an indicator of chondrocyte differentiation (Atsumi et al. 1990, Chang et al. 1998).

\section{Preparation of cell lysates}

Experiments were terminated by aspirating the culture media and washing three times with ice-cold PBS. Cell lysates were prepared in a $10 \mathrm{mM}$ Tris buffer $(\mathrm{pH} 7 \cdot 6)$ containing 1\% Triton X-100, $5 \mathrm{mM}$ EDTA, $50 \mathrm{mM}$ $\mathrm{NaCl}, 30 \mathrm{mM}$ sodium pyrophosphate, $50 \mathrm{mM} \mathrm{NaF}$, $0.1 \mathrm{mM}$ sodium orthovanadate and protease inhibitors $(10 \mu \mathrm{g} / \mathrm{ml}$ leupeptin, $10 \mu \mathrm{g} / \mathrm{ml}$ aprotinin and $25 \mu \mathrm{g} / \mathrm{ml}$ PMSF). Lysates were centrifuged at $15000 \boldsymbol{g}$ for $20 \mathrm{~min}$ at $4{ }^{\circ} \mathrm{C}$ in a micro-centrifuge. Protein content of the clarified lysate was determined by using the bicinchoninic acid method (BCA; Pierce Biotechnology, Rockford, IL, USA). Cell lysates were stored at $-80{ }^{\circ} \mathrm{C}$ until use.

\section{Western blotting}

Following standard PAGE, proteins were transferred to PVDF membranes. Immunoblots were blocked in 5\% milk in Tris-buffered saline with $0 \cdot 1 \%$ Tween-20 and probed overnight with primary antibody at a concentration of 1:1000. Results were visualized using the ECL Plus detection kit and quantified using Gel-Pro Analyzer software (Media Cybernetics, Silver Spring, MD, USA). Where indicated, blots were stripped according to the ECL Plus protocol prior to re-probing.

\section{${ }^{3}$ H]Thymidine incorporation}

Cells were incubated with $1 \mu \mathrm{Ci} /$ well $\left[{ }^{3} \mathrm{H}\right]$ thymidine for $6 \mathrm{~h}$ followed by lysis in $0.33 \mathrm{M} \mathrm{NaOH}$. An aliquot was removed for protein assay before DNA precipitation with ice-cold 40\% trichloroacetic acid/1.2 M HCl and collection on glass fiber filters for scintillation counting (Curran et al. 1993).

\section{PCR}

For determinations of collagen X expression in ATDC5 cells, total RNA was prepared using Tri-Reagent. Primer sequences used for detection of type $\mathrm{X}$ collagen and $\beta$-actin mRNAs were those used by Negishi et al. (2000). After reverse transcription, PCR was performed for 16 cycles for $\beta$-actin and 23 cycles for type $\mathrm{X}$ collagen. The optimal cycle number was determined empirically in each case to maximize the sensitivity of quantification. PCR products were electrophoresed in 1.5\% agarose gels containing ethidium bromide. Resulting photographs were quantified as described above for Western blots. For analysis of collagen $\mathrm{X}$ expression in primary chick chondrocyte cultures, real-time PCR was performed as described previously (Wu \& Chen 2000).

\section{Statistical analyses}

All data are shown as means \pm S.D. Multiple comparisons were performed using analysis of variance with Tukey's post-hoc test.

\section{Results}

Studies on ATDC5 cells have routinely employed the addition of high concentrations of insulin $(10 \mu \mathrm{g} / \mathrm{ml})$ to 


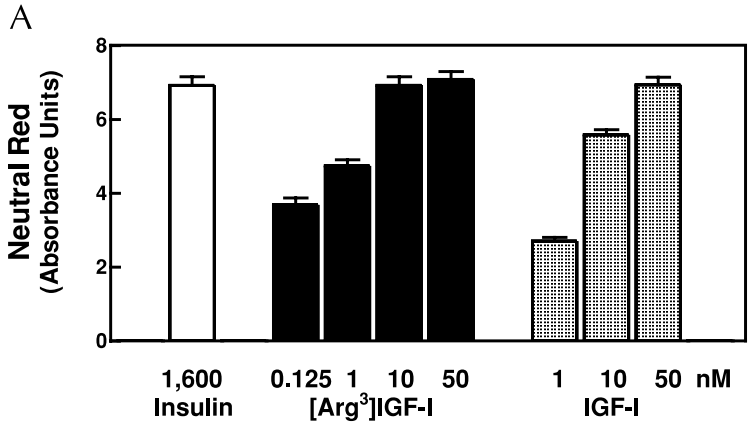

B

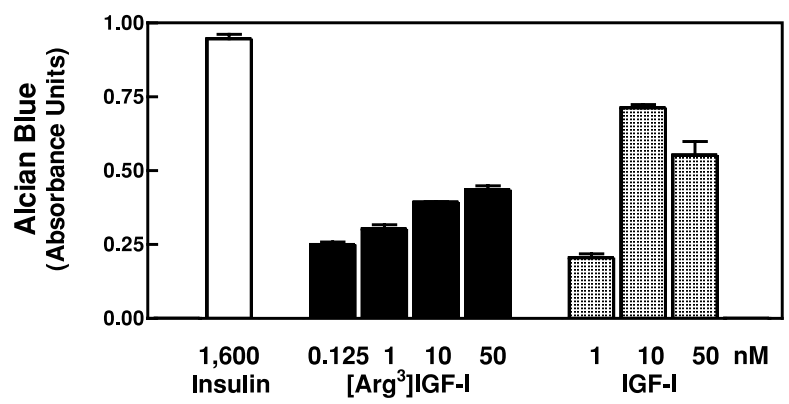

Figure 1 The effect of insulin and IGF-I on ATDC5 differentiation. ATDC5 cells were exposed to differentiating medium containing the standard concentration of insulin (1600 nM; unfilled bars) and various concentrations of [ $\mathrm{Arg}^{3}$ ]IGF-I (solid bars) or IGF-I (shaded bars). Cells were harvested at day 14 and stained with Neutral Red (A) or Alcian Blue (B). Results ( $n=3$ per condition) represent the absorbance of the extracted dye. These results were confirmed in two additional experiments.

induce chondrocyte differentiation. Based on the current understanding of insulin and IGF-I receptor signaling, we considered the possibility that the action of insulin to induce chondrocyte differentiation might be mediated through IGF-I receptors and not insulin receptors. We therefore compared the ability of physiologic concentrations of IGF-I, the [ $\left.\mathrm{Arg}^{3}\right]$ IGF-I analog and high-dose insulin to promote the proliferation and differentiation of ATDC5 cells. [ $\left.\mathrm{Arg}^{3}\right]$ IGF-I was employed so as to avoid the potential inhibitory effects of endogenous IGF-binding proteins.

To obtain hypertrophic chondrocytes, cells were first grown to confluence. They were then maintained in differentiating media as described above for 14 days. During that time, the various concentrations of $\left[\mathrm{Arg}^{3}\right]$ IGF-I, IGF-I or insulin were maintained by changing media every 2 days. Over the 14-day differentiation period, total cellular material, as indicated by Neutral Red staining, increased in response to both $\left[\mathrm{Arg}^{3}\right]$ IGF-I and IGF-I as well as cells maintained in standard insulin $(10 \mu \mathrm{g} / \mathrm{ml}$; Fig. 1A). When the growth response to the varying concentrations of $\left[\mathrm{Arg}^{3}\right]$ IGF-I and IGF-I were compared using Neutral Red staining, the apparent order
A

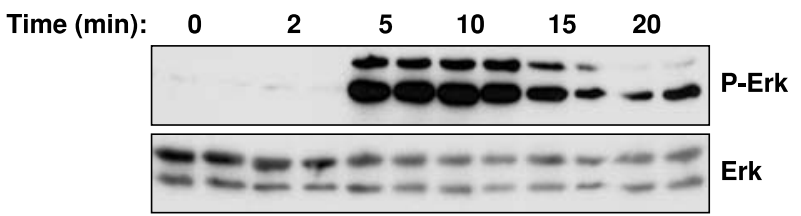

B

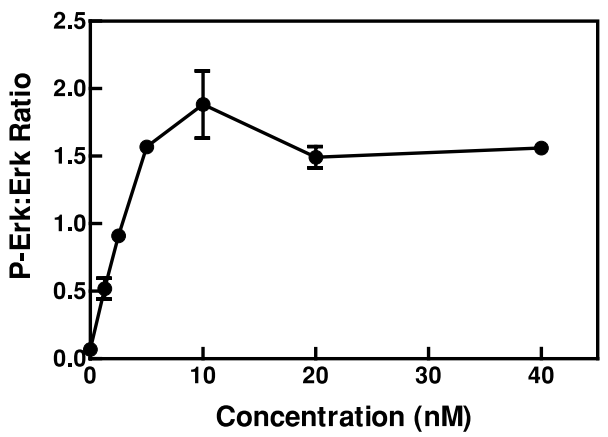

Figure 2 The activation of ERK1 and ERK2 by IGF-I. Proliferating ATDC 5 cells were serum starved for $4 \mathrm{~h}$, then incubated with IGF-I. Cell lysates were prepared and analyzed by Western immunoblotting for phosphorylated ERK1/ERK2 (P-Erk) and total ERK1/ERK2. (A) Cells were incubated with 40 nM IGF-I for 2-20 min. (B) Cells were exposed to various concentrations of IGF-I for $5 \mathrm{~min}$. Results are shown as means \pm S.D.

of potency was $\left[\mathrm{Arg}^{3}\right]$ IGF-I>IGF-I. Differentiation, measured as Alcian Blue staining, also increased in response to all three agents. However, the results (Fig. 1B) showed a potency of IGF-I $>\left[\mathrm{Arg}^{3}\right]$ IGF-I. While Neutral Red staining increased in proportion to IGF-I concentration, a decline in Alcian Blue staining was seen when the IGF-I concentration was increased from 10 to $50 \mathrm{nM}$. The $\left[\mathrm{Arg}^{3}\right]$ IGF-I response was proportional to concentration, but rather limited at all concentrations relative to the maximal effect of insulin at high concentration. These results were interpreted as indicating that all three agents could stimulate chondrocyte differentiation, but that a simple, proportional dose response to IGF-I or $\left[\mathrm{Arg}^{3}\right] \mathrm{IGF}-\mathrm{I}$ might be confounded by stimulation of proliferation.

To clarify the interpretation of these results, we performed studies to assess the mitogenic potency of IGF-I. Given the key role of the ERK pathway in growth factor-induced proliferation, we focused on this signaling pathway. Proliferating ATDC5 cells were incubated in serum-free medium for $4 \mathrm{~h}$. They were then exposed to a concentration of IGF-I $(40 \mathrm{nM})$ that has been shown previously to be efficacious (Hidaka et al. 2001). ERK activation, measured by Western blotting for the phosphorylated, active forms of ERK1 and ERK2, occurred within 5 min of IGF-I exposure (Fig. 2A). Dose-response curves for IGF-I showed that IGF-I concentrations as 


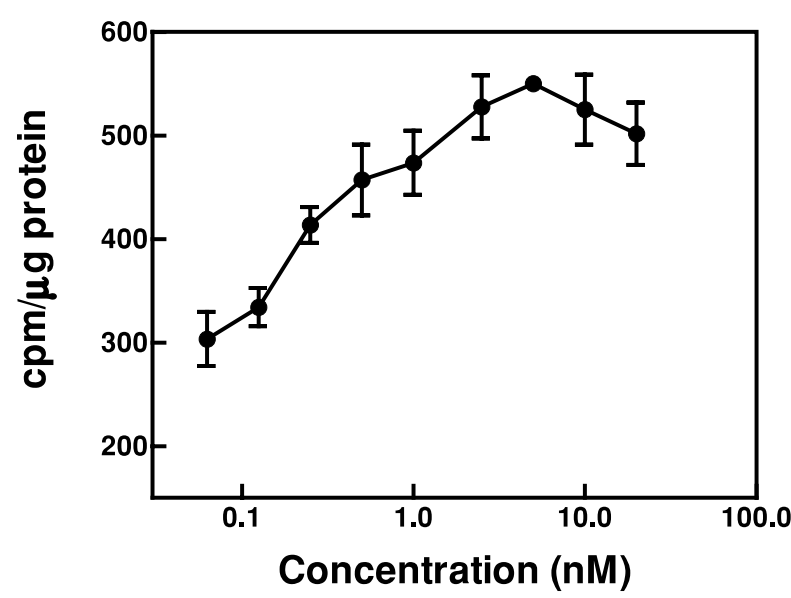

Figure 3 The effect of insulin and $\left[\mathrm{Arg}^{3}\right]$ IGF-I on $\left[{ }^{3} \mathrm{H}\right]$ thymidine incorporation by ATDC5 cells. Subconfluent ATDC5 cells were serum starved overnight, then treated with $\left[\mathrm{Arg}^{3}\right]$ IGF-I for $24 \mathrm{~h}$ at concentrations ranging from 0 to $80 \mathrm{nM}$. $6 \mathrm{~h}$ prior to the completion of this incubation period $\left[{ }^{3} \mathrm{H}\right]$ thymidine $(1 \mu \mathrm{Ci} /$ well $)$ was added. Results are means \pm S.D. for $n=3$ per condition. Two additional experiments (not shown) gave similar results.

low as $10 \mathrm{nM}$ could induce maximal ERK activation (Fig. 2B). The ability of the $\left[\mathrm{Arg}^{3}\right]$ IGF-I to induce ERK activation was similar to that observed for IGF-I (data not shown).

The ERK response data suggested that IGF-I is a potent mitogen for these cells at what would be considered physiological concentrations. This was tested directly by measuring DNA synthesis as incorporation of $\left[{ }^{3} \mathrm{H}\right]$ thymidine. $\left[\mathrm{Arg}^{3}\right]$ IGF-I was used for this experiment in order to avoid inhibitory effects of endogenous IGF-binding proteins for the long duration of exposure $(24 \mathrm{~h})$. Results (Fig. 3) demonstrated that $\left[\mathrm{Arg}^{3}\right]$ IGF-I could induce maximal ATDC5 cell DNA synthesis at a concentration as low as $6 \mathrm{nM}$.

As noted above, we considered the possibility that the limited ability of $\left[\mathrm{Arg}^{3}\right]$ IGF-I and IGF-I to induce differentiation might be secondary to their potent mitogenic effects. A series of experiments was performed to test this hypothesis. We first determined the effect of inhibition of ERK pathway activation on the mitogenic effect of IGF-I. This was accomplished by using PD98059, a specific inhibitor of the intermediate kinases (mitogen-activated protein kinase/ERK kinases (MEKs) 1 and 2) in the ERK pathway. To first demonstrate the effect of MEK inhibition on ERK activation by IGF-I, cells were treated with 0,20 or $50 \mu \mathrm{M}$ PD98059 (the DMSO vehicle content was held constant) for $1 \mathrm{~h}$ prior to addition of $5 \mathrm{nM}$ IGF-I for $5 \mathrm{~min}$. As expected, PD98059 at $50 \mu \mathrm{M}$ inhibited IGF-I-mediated ERK activation by approximately $70 \%$ (Fig. 4A). To examine the effect of MEK inhibition on DNA synthesis, cells were treated with $50 \mu \mathrm{M}$ PD98059 $1 \mathrm{~h}$ before addition of IGF-I. Cells were incubated for an additional $24 \mathrm{~h}$ with $1 \mu \mathrm{Ci} /$ well $\left[{ }^{3} \mathrm{H}\right]$ thymidine added for
A

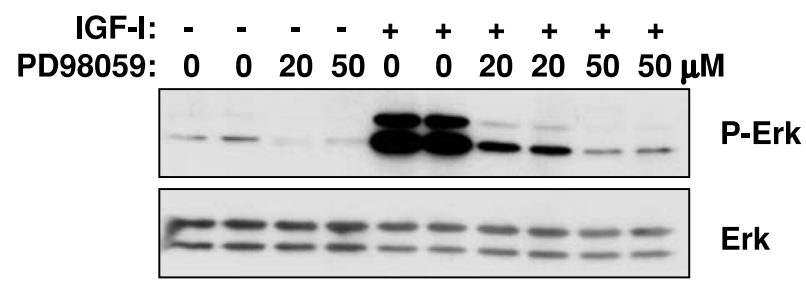

B

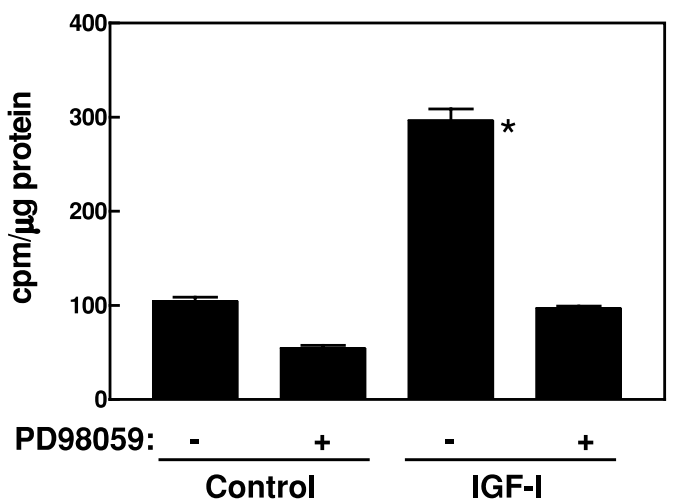

Figure 4 The effect of the MEK inhibitor, PD98059, on ERK activation and $\left[{ }^{3} \mathrm{H}\right]$ thymidine incorporation in ATDC5 cells. (A) Proliferating ATDC5 cells were serum starved for $4 \mathrm{~h}$. Cells were then exposed to PD98059 at 0,20 or $50 \mu \mathrm{M}$ for $1 \mathrm{~h}$ after which $5 \mathrm{nM}$ IGF-I was added for 5 min to selected wells as indicated $(-$ or +$)$. Cell lysates were prepared and analyzed by Western immunoblotting for phosphorylated ERK1/ERK2 (P-Erk) and total ERK1/ERK2. (B) Subconfluent ATDC5 cells were serum starved overnight. Cells were then exposed to DMSO $(-)$ or PD98059 (+) without or with IGF-I for $24 \mathrm{~h}$. During the last $6 \mathrm{~h}$, $\left[{ }^{3} \mathrm{H}\right]$ thymidine $(1 \mu \mathrm{Ci} /$ well $)$ was included. Results, showing incorporation of $\left[{ }^{3} \mathrm{H}\right]$ thymidine into DNA per $\mu \mathrm{g}$ protein, represent $n=3$ for each condition. ${ }^{*} P<0 \cdot 05$ versus all other groups.

the final $6 \mathrm{~h}$ of the incubation period. Results from $\left[{ }^{3} \mathrm{H}\right]$ thymidine incorporation (Fig. 4B) showed that, under both unstimulated and IGF-I-stimulated conditions, this concentration of PD98059 was sufficient to decrease DNA synthesis by $75-80 \%$.

In our initial experiments we observed that increasing the concentration of IGF-I from 10 to $50 \mathrm{nM}$ was associated with a decreased induction of ATDC5 differentiation (Fig. 1B). This finding was supported further by correcting Alcian Blue staining for total cellular material, as quantified by Neutral Red staining (Fig. 5A). Parallel experiments were performed to compare the concentration dependence of differentiation with that of ERK activation. ATDC5 cells were induced to differentiate with various concentration of IGF-I. At 14 days, the cells were harvested. Results (Fig. 5B) confirmed an inverse relationship between Alcian Blue staining and steady-state ERK 


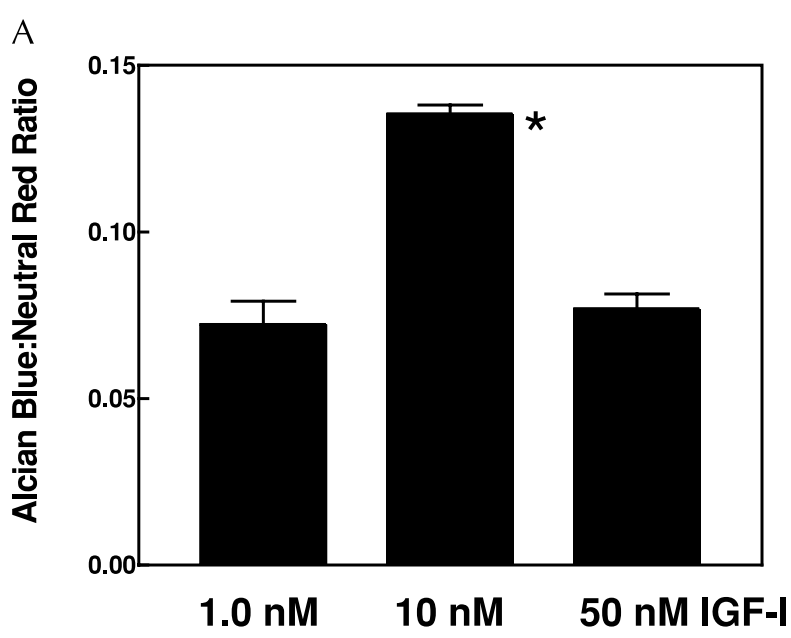

B

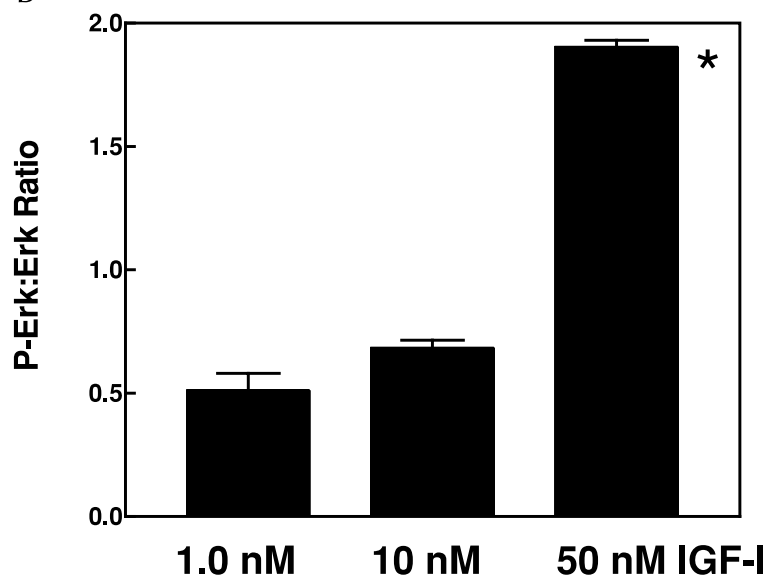

Figure 5 The effects of IGF-I on ATDC5 cell differentiation and ERK activation. ATDC5 cells were cultured in differentiating medium containing 1, 10 or 50 nM IGF-I for 14 days. One set of cells was stained using Alcian Blue and Neutral Red (A). The dyes were extracted and absorbance determined. The ratio of Alcian Blue to Neutral Red was calculated ( $n=3$ for each condition). Parallel wells were used to perform a Western immunoblot analysis for phospho-ERK (P-Erk) and total ERK (B). The ratio of phospho-ERK to total ERK was calculated ( $n=3$ for each condition). ${ }^{*} P<0 \cdot 05$ versus other groups. A replicate experiment (not shown) gave the same results.

phosphorylation. Similar results were obtained in additional experiments that used $\left[\mathrm{Arg}^{3}\right]$ IGF-I to induce differentiation (data not shown).

To confirm that ERK activation impairs the ability of IGF-I to promote chondrocyte proliferation, we examined the ability of PD98059 to amplify the differentiating effect of IGF-I. PD98059 and IGF-I were maintained in the culture media during the entire 14-day differentiation period, at the end of which cell lysates were prepared. Cells continually exposed to PD98059 plus IGF-I showed

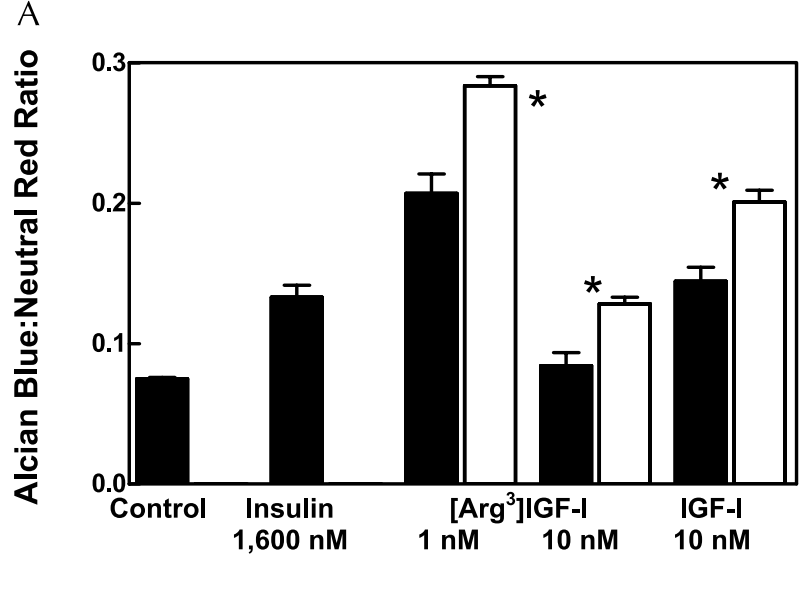

B

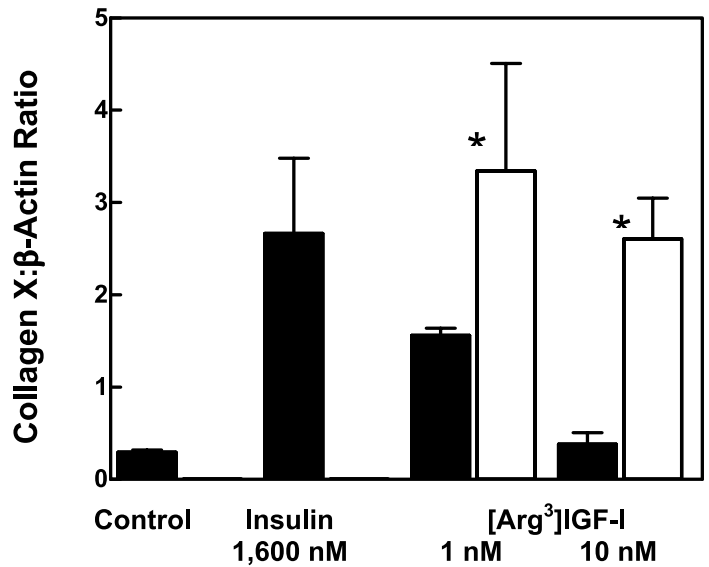

Figure 6 The effect of MEK inhibition by PD98059 on ATDC5 differentiation. Cells were cultured for 14 days in differentiating medium without growth factors (control) or in differentiating medium containing $1600 \mathrm{nM}$ insulin, 1 or $10 \mathrm{nM}\left[\mathrm{Arg}^{3}\right] \mathrm{IGF}-\mathrm{I}$, or 10 nM IGF-I. Solid bars and open bars represent cells that were maintained in the absence or presence of $50 \mu \mathrm{M}$ PD98059 respectively. Media were changed every other day for the duration of the experiment. Two markers of differentiation were assessed. (A) Cells were stained with Alcian Blue. The dye was extracted and optical density measured. Data represent $n=3$ for each condition. (B) A similar experiment was performed in which cells were lysed for preparation of total RNA. Collagen $X$ and $\beta$-actin expression were assessed using semi-quantitative reverse transcriptase PCR. The ratio of collagen $X$ to $\beta$-actin expression is shown ( $n=3$ for each condition). ${ }^{*} P<0 \cdot 05$ versus the corresponding control group.

a greater degree of differentiation, as demonstrated by both Alcian Blue staining (Fig. 6A) and collagen X expression (Fig. 6B), than cells exposed to IGF-I alone. The results of the latter analysis were particularly impressive, with PD98059 converting the $\left[\mathrm{Arg}^{3}\right]$ IGF-I from a differentiating factor that was far less potent than insulin to one that was as potent as $1600 \mathrm{nM}$ insulin. 


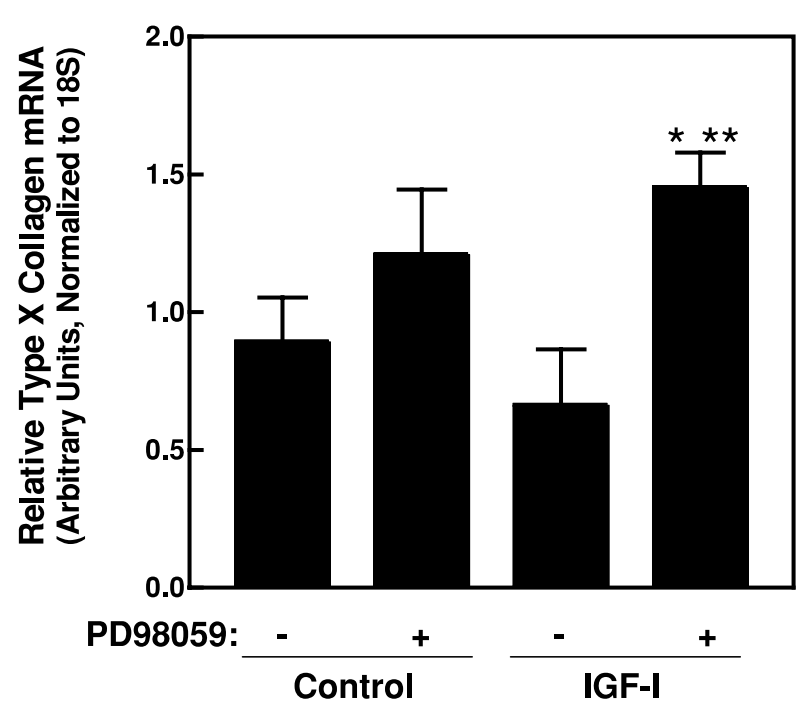

Figure 7 The effect of MEK inhibition by PD98059 on chick chondrocyte differentiation. Chick chondrocytes were maintained in culture for 3 days post-confluence in the absence $(-)$ or presence (+) of PD98059 and/or 10 nM IGF-I. At the end of that time, total RNA was prepared. Collagen X expression, normalized to $18 \mathrm{~S}$ RNA content, was determined by real-time PCR. Results represent $n=3$ for each condition. ${ }^{*} P<0 \cdot 05$ versus control, no PD98059; ${ }^{* *} P<0 \cdot 01$ versus IGF-I, no PD98059.

To further study the effect of PD98059 on chondrocyte differentiation, we obtained proliferating primary chick chondrocytes from the caudal region of 17-day embryonic chicken sternal cartilage. These proliferating chondrocytes, when maintained in culture for several days, gradually differentiate into hypertrophic chondrocytes as indicated by increased collagen $\mathrm{X}$ expression. For this experiment, we performed real-time PCR to measure collagen $\mathrm{X}$ expression in proliferating chick chondrocytes maintained in culture for 3 days after achieving confluence (Fig. 7). As expected, we observed an increase in collagen X expression in all samples. When PD98059 was added to the culture media, collagen X expression showed an upward trend but did not reach statistical significance. However, when IGF-I and PD98059 were both added to the culture media, a significant increase in collagen $\mathrm{X}$ expression was observed. Based on these results, we reasoned that IGF-I acts as a more potent differentiating agent for chondrocytes if its ability to activate the ERK pathway is attenuated as the cells differentiate.

In order to test this hypothesis, we performed a series of experiments comparing the ERK response to IGF-I in proliferating and hypertrophic chondrocytes. The latter condition was verified by demonstrating induction of collagen $\mathrm{X}$ and Alcian Blue staining. First, proliferating ATDC5 cells were changed to serum-free media for $4 \mathrm{~h}$ and then stimulated acutely with $5 \mathrm{nM}$ IGF-I. Results (Fig. 8A) showed the expected potent ERK activation in proliferating cells. We then induced differentiation

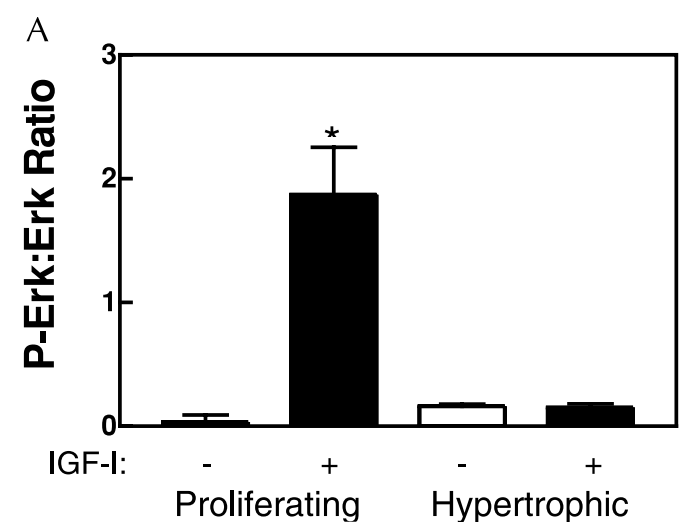

B

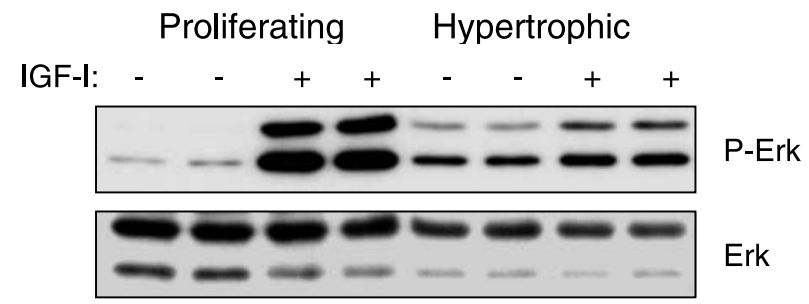

C

\section{Proliferating Hypertrophic}

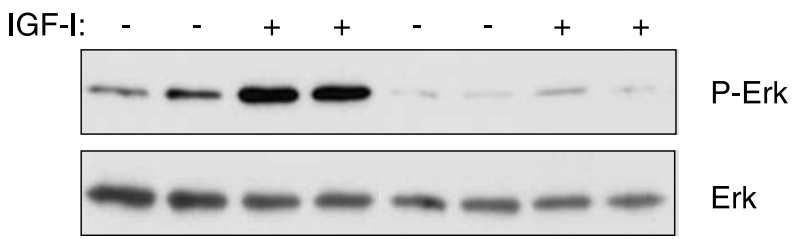

Figure 8 Modulation of IGF-I mitogenic signaling during chondrocyte differentiation. ERK activation in response to IGF-I was compared using proliferating and hypertrophic chondrocytes. Cells were serum starved for $4 \mathrm{~h}$ prior to incubation with $5 \mathrm{nM}$ IGF-I for $5 \mathrm{~min}$. Cell lysates were prepared for Western immunoblotting with antibodies directed towards phosphorylated (P-Erk) and total ERK1/ERK2. (A) Data for triplicate determinations using ATDC5 cells. (B) A representative analysis of an experiment using RCJ3.1C5.18 cells; (C) an analogous experiment using primary chick chondrocytes. ${ }^{*} P<0 \cdot 005$ versus all other groups.

by adding a high concentration of insulin to confluent ATDC5 cells to obtain the fully differentiated cells in 2 weeks' time. When differentiation was achieved, ATDC5 cells were changed to serum-free media for $4 \mathrm{~h}$ and then stimulated acutely with $5 \mathrm{nM}$ IGF-I. Minimal ERK activation in response to IGF-I was observed in these differentiated cultures (Fig. 8A). To determine if these findings were specific to ATDC5 cells or of more general significance, similar experiments were performed in two other systems, RCJ3·1C5.18 cells (Fig. 8B) and primary chick chondrocyte cultures (Fig. 8C). Similar results were observed in both model systems. 


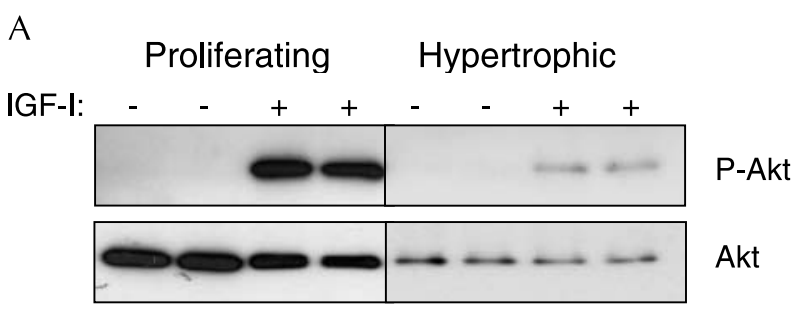

B
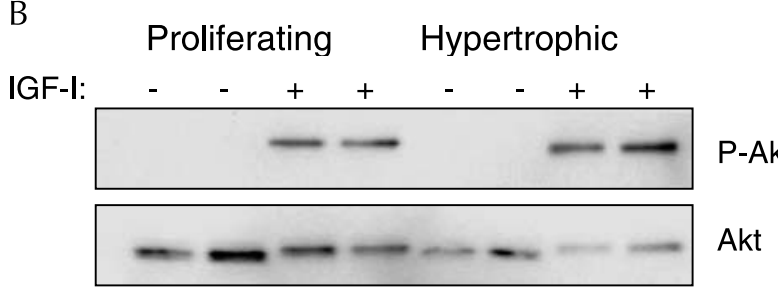

C

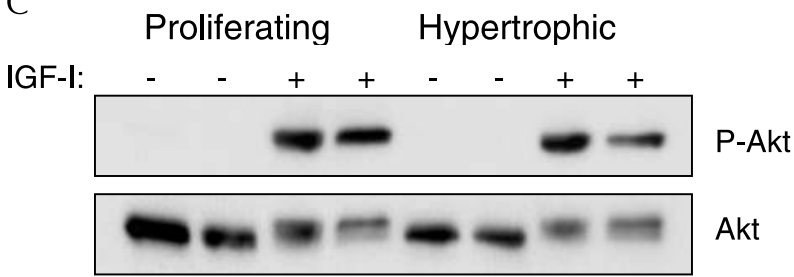

Figure 9 IGF-I signaling to Akt during chondrocyte differentiation. Akt activation in response to IGF-I was examined in proliferating and hypertrophic chondrocyte cultures. Cells were serum starved for $4 \mathrm{~h}$ prior to incubation with $5 \mathrm{nM}$ IGF-I for $5 \mathrm{~min}$. Cell lysates were prepared for Western immunoblotting with antibodies directed towards phosphorylated (P-Akt) and total Akt. Results are shown for ATDC5 cells (A), RCJ3·1C $5 \cdot 18$ cells (B) and primary chick chondrocytes $(\mathrm{C})$.

To determine if this loss of signaling in hypertrophic chondrocytes could be attributed to decreased signaling at the receptor or immediate-post-receptor level, the samples were analyzed for phosphorylation of Akt, an indirect indicator of Akt activation. The rationale for examining Akt was the locus of this signaling kinase in the PI 3-kinase-dependent pathway, one that is distinct from that involved in ERK activation. Results (Fig. 9) demonstrated that IGF-I could potently activate Akt in both proliferating and hypertrophic chondrocytes in all three model systems. This result was consistent with the observation that IGF-I receptors are present in hypertrophic chondrocytes (Olney \& Mougey 1999). To eliminate the possibility that the ERK response to IGF-I might be delayed in the hypertrophic cells, we performed a time course extending to $2 \mathrm{~h}$ after addition of IGF-I. At all time points, the ERK response to IGF-I was markedly attenuated (data not shown).

\section{Discussion}

The ATDC5 cell line, originally derived from a mouse teratocarcinoma, has been used by a number of investigators as a model for chondrocyte differentiation (Shukunami et al. 1996, Watanabe et al. 2001). Insulin concentrations sufficiently high to interact with the IGF-I receptor are routinely used to induce maximal ATDC5 cell diffentiation. We therefore undertook a direct study of the role of IGF-I in these cells. We considered the possibility that IGF-I might not only be acting through IGF-I receptors but also through insulin:IGF-I hybrid receptors. However, functional studies of hybrid receptors suggest that they behave more like IGF-I receptors than insulin receptors. They bind to and are activated by IGF-I with an affinity similar to that of IGF-I receptors (Frattali \& Pessin 1993, Pandini et al. 2002). Therefore, the presence of hybrid receptors on ATDC5 cells would not necessarily alter our interpretation of the IGF-I signaling data.

We found that increasing concentrations of IGF-I did not show a direct relationship to potency for inducing ATDC5 differentiation, a finding that was not observed when insulin was used. A similar observation was made when we used $\left[\mathrm{Arg}^{3}\right]$ IGF-I to induce chondrocyte differentiation. This biphasic concentration-dependence for IGF-I-mediated differentiation was inversely related to the steady-state levels of ERK phosphorylation. That is, attenuated differentiation at the higher IGF-I concentrations correlated with greater ERK activation. This finding, taken together with the ability of an ERK pathway inhibitor to potentiate the differentiating effects of IGF-I, supports the conclusion that ERK activation by IGF-I inhibits its differentiating effects.

As noted above, both proliferating and hypertrophic chondrocytes are exposed to locally produced IGF-I in vivo. Given that normal chondrocytes (Olney \& Mougey 1999) and ATDC5 cells (Shukunami et al. 1996) express the IGF-I receptor at all stages of their development, and that activation of a key mitogenic pathway was inhibitory for differentiation, we hypothesized that IGF-I signaling might be modulated during chondrogenesis. Indeed, we were able to demonstrate a marked reduction in IGF-I-mediated ERK activation in growth arrested and hypertrophic chondrocytes using two additional chondrogenic cell models. We were able to confirm that this change in IGF-I signaling cannot be explained by loss of IGF-I receptor expression or activation, as indicated by the maintenance of IGF-I signaling to Akt. Similar downregulation of the ERK pathway has been demonstrated to occur during myogenesis and adipogenesis (Boney et al. 1996, Milasincic et al. 1996). In both cases, it has been proposed that downregulation of the ERK pathway may be an important component of the IGF-I signal transduction mechanisms required to induce mesenchymal differentiation. The replication of our findings in two chondrogenic cell lines and primary chick chondrocytes 
indicates that this shift in IGF-I signaling may well be of physiological significance. The critical role of ERK downregulation during chondrocyte differentiation is also supported by studies on chondrocytes derived from mice made transgenic for constitutively active MEK1 (Murakami et al. 2004). These mice displayed incomplete hypertrophy of chondrocytes in the growth plates, while chondrocyte proliferation was unaffected.

In summary, our findings provide compelling support for a key role of IGF-I in both chondrocyte proliferation and differentiation. The modulation of IGF-I signaling that we observed when chondrocytes convert from a proliferative to hypertrophic state is consistent with a paradigm that is emerging in other models of mesenchymal cell differentiation. This change in signaling appears to be essential for a dual role of IGF-I in the promotion of chondrocyte proliferation and differentiation at the growth plate.

\section{Acknowledgements}

We thank Ms Joan Boylan, Dr Charlotte Boney and Dr Edward Filardo for their expertise, advice and assistance in the performance of these studies. This work was supported by the following USPHS grants: HD24455, HD35831 and DK59815 to P A G; R01AG014399 and R01AG017021 to Q C. Q C is also supported by a grant from the Arthritis Foundation. C P derives support from P20RR017695 and from the Rhode Island Hospital Department of Pediatrics Research Endowment Funds. The authors declare that there is no conflict of interest that would prejudice the impartiality of this scientific work.

\section{References}

Atsumi T, Miwa Y, Kimata K \& Ikawa Y 1990 A chondrogenic cell line derived from a differentiating culture of AT805 teratocarcinoma cells. Cell Differentiation and Development 30 109-116.

Benito M, Valverde AM \& Lorenzo M 1996 IGF-I: a mitogen also involved in differentiation processes in mammalian cells. International Journal of Biochemistry and Cell Biology 28 499-510.

Boney CM, Fiedorek FT Jr, Paul SR \& Gruppuso PA 1996 Regulation of preadipocyte factor-1 gene expression during 3T3-L1 cell differentiation. Endocrinology 137 2923-2928.

Boney CM, Smith RM \& Gruppuso PA 1998 Modulation of insulin-like growth factor I mitogenic signaling in 3T3-L1 preadipocyte differentiation. Endocrinology 139 1638-1644.

Cancedda R, Descalzi CF \& Castagnola P 1995 Chondrocyte differentiation. International Review of Cytology 159 265-358.

Chang S-H, Oh C-D, Yang M-S, Kang S-S, Lee Y-S, Sonn J-K \& Chun J-S 1998 Protein kinase C regulates chondrogenesis of mesenchymes via mitogen-activated protein kinase signaling. Journal of Biological Chemistry 273 19213-19219.

Curran TR Jr, Bahner RI Jr, Oh W \& Gruppuso PA 1993 Mitogen-independent DNA synthesis by fetal rat hepatocytes in primary culture. Experimental Cell Research 209 53-57.

Daughaday WH \& Rotwein P 1989 Insulin-like growth factors I and II. Peptide, messenger ribonucleic acid and gene structures, serum, and tissue concentrations. Endocrine Reviews 10 68-91.
Frattali AL \& Pessin JE 1993 Relationship between alpha subunit ligand occupancy and beta subunit autophosphorylation in insulin/insulin-like growth factor-1 hybrid receptors. Journal of Biological Chemistry 268 7393-7400.

Grigoriadis AE, Heersche JN \& Aubin JE 1996 Analysis of chondroprogenitor frequency and cartilage differentiation in a novel family of clonal chondrogenic rat cell lines. Differentiation $\mathbf{6 0}$ 299-307.

Hidaka K, Kanematsu T, Takeuchi H, Nakata M, Kikkawa U \& Hirata M 2001 Involvement of the phosphoinositide 3-kinase/protein kinase B signaling pathway in insulin/IGF-I-induced chondrogenesis of the mouse embryonal carcinoma-derived cell line ATDC5. International Journal of Biochemistry and Cell Biology 33 1094-1103.

Kronenberg HM 2003 Developmental regulation of the growth plate. Nature 423 332-336.

Kull FC \& Cuatrecasas P 1983 Estimation of cell number by neutral red content: application for proliferative and survival assays. Applied Biochemistry and Biotechnology 8 97-103.

Liu JL, Grinberg A, Westphal H, Sauer B, Accili D, Karas M \& LeRoith D 1998 Insulin-like growth factor-I affects perinatal lethality and postnatal development in a gene dosage-dependent manner: manipulation using the Cre/loxP system in transgenic mice. Molecular Endocrinology 12 1452-1462.

Lupu F, Terwilliger JD, Lee K, Segre GV \& Efstratiadis A 2001 Roles of growth hormone and insulin-like growth factor 1 in mouse postnatal growth. Developmental Biology 229 141-162.

Milasincic DJ, Calera MR, Farmer SR \& Pilch PF 1996 Stimulation of $\mathrm{C} 2 \mathrm{C} 12$ myoblast growth by basic fibroblast growth factor and insulin-like growth factor 1 can occur via mitogen-activated protein kinase-dependent and -independent pathways. Molecular Cell Biology 16 5964-5973.

Murakami S, Balmes G, McKinney S, Zhang Z, Givol D \& de Crombrugghe B 2004 Constitutive activation of MEK1 in chondrocytes causes Stat1-independent achondroplasia-like dwarfism and rescues the Fgfr3-deficient mouse phenotype. Genes and Development 18 290-305.

Negishi Y, Kudo A, Obinata A, Kawashima K, Hirano H, Yanai N, Obinata M \& Endo H 2000 Multipotency of a bone marrow stromal cell line, TBR31-2, established from ts-SV40 T antigen gene transgenic mice. Biochemical and Biophysical Research Communications 268 450-455.

Ohlsson C, Isaksson O \& Lindahl A 1994 Clonal analysis of rat tibia growth plate chondrocytes in suspension culture-differential effects of growth hormone and insulin-like growth factor I. Growth Regulation 4 1-7.

Olney RC \& Mougey EB 1999 Expression of the components of the insulin-like growth factor axis across the growth-plate. Molecular Cell Endocrinology 156 63-71.

Pandini G, Frasca F, Mineo R, Sciacca L, Vigneri R \& Belfiore A 2002 Insulin/insulin-like growth factor I hybrid receptors have different biological characteristics depending on the insulin receptor isoform involved. Journal of Biological Chemistry 277 39684-39695.

Schlechter NL, Russell SM, Spencer EM \& Nicoll CS 1986 Evidence suggesting that the direct growth-promoting effect of growth hormone on cartilage in vivo is mediated by local production of somatomedin. PNAS 83 7932-7934.

Shukunami C, Shigeno C, Atsumi T, Ishizeki K, Suzuki F \& Hiraki Y 1996 Chondrogenic differentiation of clonal mouse embryonic cell line ATDC5 in vitro: differentiation-dependent gene expression of parathyroid hormone (PTH)/PTH-related peptide receptor. Journal of Cell Biology 133 457-468.

Sjogren K, Liu JL, Blad K, Skrtic S, Vidal O, Wallenius V, LeRoith D, Tornell J, Isaksson OG, Jansson JO \& Ohlsson C 1999 Liver-derived insulin-like growth factor I (IGF-I) is the principal source of IGF-I in blood but is not required for postnatal body growth in mice. PNAS 96 7088-7092. 
van der Eerden BC, Karperien M \& Wit JM 2003 Systemic and local regulation of the growth plate. Endocrine Reviews 24 782-801.

Van Wyk JJ \& Smith EP 1999 Insulin-like growth factors and skeletal growth: possibilities for therapeutic interventions. Journal of Clinical Endocrinology and Metabolism 84 4349-4354.

Watanabe H, de Caestecker MP \& Yamada Y 2001 Transcriptional cross-talk between Smad, ERK1/2, and p38 mitogen-activated protein kinase pathways regulates transforming growth factor-beta-induced aggrecan gene expression in chondrogenic ATDC5 cells. Journal of Biological Chemistry 276 14466-14473.

Werner H \& Le Roith D 2000 New concepts in regulation and function of the insulin-like growth factors: implications for understanding normal growth and neoplasia. Cell and Molecular Life Sciences 57 932-942.

Wu QQ \& Chen Q 2000 Mechanoregulation of chondrocyte proliferation, maturation, and hypertrophy: ion-channel dependent transduction of matrix deformation signals. Experimental Cell Research 256 383-391.
Yakar S, Liu JL, Stannard B, Butler A, Accili D, Sauer B \& LeRoith D 1999 Normal growth and development in the absence of hepatic insulin-like growth factor I. PNAS 96 7324-7329.

Zhen X, Wei L, Wu Q, Zhang Y \& Chen Q 2001

Mitogen-activated protein kinase p38 mediates regulation of chondrocyte differentiation by parathyroid hormone. Journal of Biological Chemistry 276 4879-4885.

Zhou Y, Xu BC, Maheshwari HG, He L, Reed M, Lozykowski M, Okada S, Cataldo L, Coschigamo K, Wagner TE et al. 1997 A mammalian model for Laron syndrome produced by targeted disruption of the mouse growth hormone receptor/binding protein gene (the Laron mouse). PNAS 94 13215-13220.

Received 10 August 2004

Accepted 7 September 2004

Made available online as an

Accepted Preprint 15 September 2004 